\title{
Logical Automatic Water Control System For Domestic Applications
}

\author{
Hassan Jamal
}

\begin{abstract}
It has been noted that water crisis are reaching at alarming proportion in Pakistan, due to miss management and low literacy rate. Most of households use water pump to get fresh ground water and fill there overhead tanks, but due to less technical involvement enormous amount of the water is wasted. Automatic water control system provides significant solution to this issue. Methodology of this system is all depend on the electric conductivity of water and logical signals given to different logic gates. This system terminates the water pump from over flow and also shows indication at different levels of water in overhead tank.
\end{abstract}

Keywords-automatic water control system; overhead tanks; electrical conductivity; logical gates

\section{INTRODUCTION}

Pakistan and rest of the world had a major problem to provide fresh water to the growing population of the world, especially over the past 25 years the population of the Pakistan almost become double. (According to Pakistan census report of 1989 and 2015) Pakistan had 107.9 million populations in 1989 and 189.87 million populations in 2015 with growing rate of $1.49 \%$ every year.

Particularly in big cities of Pakistan for instance, in Lahore there is a twin problem related to drinking water that is surface water is contaminated whereas sub surface water table is falling at high rate. There is only one option left that is water management, which can be achieved to stop the wastage of fresh water particularly from unnecessary wastage of water due to overflow in Overhead Tanks in many houses. Automatic Water Level Controller can provide a solution to this problem.

Consequently, automatic controlling involves designing a control system to function with minimal or no human interference. Last few decades several monitoring system integrated with water level detection have become accepted. Many researchers proposed many similar solutions to that particular problem [2][10].

The automatic water level controller designed here is all base on the concept of electric conductivity of water.

Department of Electrical Engineering

University of Engineering and Technology, Taxila Taxila, Pakistan

The probes will detect the level of water and automatically ON/OFF the water pump and give information about the amount of water in overhead tank by using different colour LEDs and high sound buzzer. This level controller used different logic gates and work on the principle of high and low logic signals given to them by the probes in the overhead water tank. This design of water controller is quite efficient, sensitive to any sudden change in water tank.

\section{METHODOLOGY}

The automatic pump controller minimizes the need for any manual switching and human interference .System operates on the behalf of water conductivity.

This system has its own power supply and solar power backup system, which provides it continuous electric supply in case of load shedding which is common in many countries. This system operates on 5 volt DC with 50 to $60 \mathrm{~Hz}$.

1) We attach supply to 220 volts and with the help of stepdown transformer we stepdown the voltage from 220AC to 9AC.Then diode bridge convert 9volt AC to 9 volt Dc and with the use of $2200 \mathrm{uF}$ capacitor we decreases the repel factor and smoothened the wave.

2) Zener Diode and Zener Resistance plays an active role in all that. It restricts the voltage and maintain 5 volt Dc as an input to our automatic water control system and power storage system.

3) This system will operate on solar energy until unless sun heat is present and when there is any change occurs in intensity of sunshine the system automatically shifts to power backup and get continuous power from storage battery

4) In case of low power backup the system shifts to WAPDA power supply.

5) In this methodology we gave earth to the water tank and place metallic contacts at the different levels of the water tank. When water filled the gap between these contacts and the adjoining circuit closed and a signal (current) flowed.

6) These signals are become the input of AND gate and its output become the input of NOT gate.

7) Its results become the signals of REST of 555 timer ic and Also signal A was fed as the Trigger input to the 555 timer IC.

8) Then the output of 555 timer ic is fed to NOT gate and at last its output become the input signal of Base of BJT Transistor which will activate and amplify the signal to that much, so it can able to Turn ON/OFF the relay connected to motor circuit. 
9) Different colour LEDs blinks at different levels of tank and High sound buzzer activated at certain level, so in order to indicate that enough of water is pumped or overhead tank is going to be filled completely.

10) Then system automatically shut down the pump and then reactivated at certain level of water in tank. As shown in Fig.2.3.

\section{RESULT AND DISCUSSION}

The circuit diagram for the proposed water level controller is given as Fig-1 which is highlighting varies components; the major components are step down transformer which is proposed to convert $220 \mathrm{v}$ Ac to $9 \mathrm{v}$ Ac which is further restricted by Zener diode to $5.6 \mathrm{v}$ Dc. This $5.6 \mathrm{v}$ Dc is required to operate integrated circuit of water level controller system. The other component is 555 Timer IC and we proposed to use its bistable mode to operate are system.

Experimental result of water level sensing unit, motor and visible level description for user by LED light had been given by table 1 which is indicating specification of three parameters that is LED, Buzzer and water pump operational behavior.

[11] Have worked on low cost automatic water level control for domestic applications and concluded there finding to preserve water. "Automatic Water Level Controller can provide a solution to this problem. The operation of water level controller works upon the fact that water conducts electricity. So water can be used to open or close a circuit. As the water level rises or falls, different circuits in the controller send different signals. These signals are used to switch ON or switch OFF the motor pump as per our requirements". Our system has advantage over the other water level controller by providing buzzer as well as it is indicating the storage level for the different storages i.e. $0 \%, 30 \%, 90 \%$ and further more red LED will be activated when water storage is $100 \%$ attained.

Comparing to Automatic water level control system by [10] which is based on controlling water level by LCD screen with buzzer where as our system is being indicated with LED. Furthermore our system has three different LEDs installed in a single panel and their leads at different water levels i.e. $0 \%$, $30 \%, 90 \%, 100 \%$ within the storage tank.

Hence it have advantage over the other water level controllers [2][3][7]. Another advantage of our system is that, it has its own low cost continuous power supply and solar energy system which provides low cost energy. The system supply work on 220v Ac and $50 \mathrm{~Hz}$ frequency. Its output is of $5.6 \mathrm{v}$ Dc which is fed to our water control system. Our system required only 0.84 Watts and it will consume 0.605 units per month. This information indicates that our system is quite efficient, economical and this compact system needs very less power to operate in active mode.

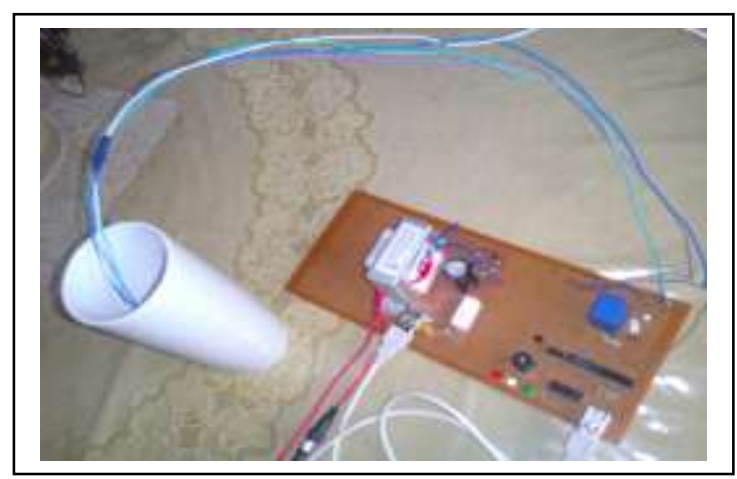

Fig. 2.1 Hard ware Implementation

\section{HARDWARE IMPLEMENTATION}

\section{REQUIRED EQUIPMENTS}

The implemented "Logical automatic water control system for domestic applications" need the following equipment's:

- 555 TIMER IC

- PROBES

- SOLAR PANEL

- DRY BATTERY

- POWER SUPPLY

- RELAYS

- LEDS

- BUZZER

- RESISTORS

- INVERTORS

- AND GATES

The hardware of the proposed system is shown in Fig 2.1

A) Working of 555 Timers IC[12]

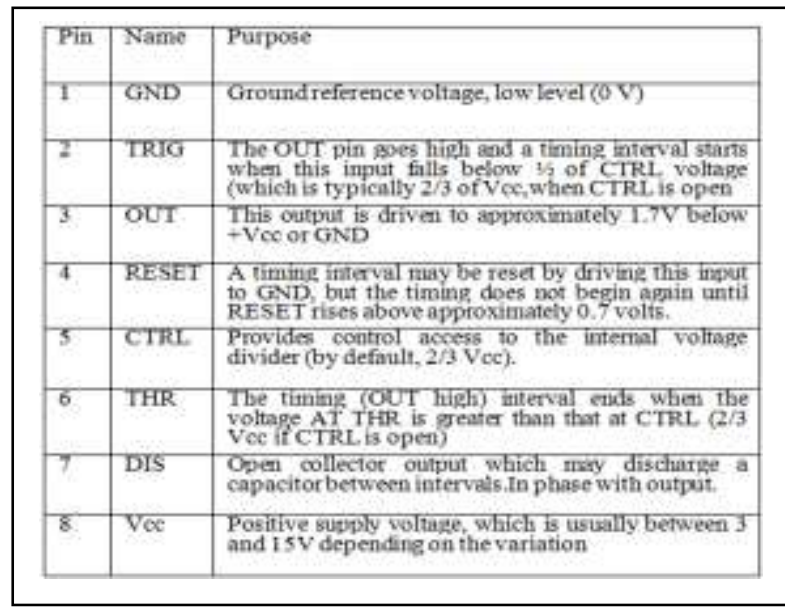

Table 1: Shows the working of 555 Timer IC pins 
Proc. of Sixth International Conference On Advances in Computing, Electronics and Electrical Technology - CEET 2016

B) Internal Circuit of 555 Timer IC[13]

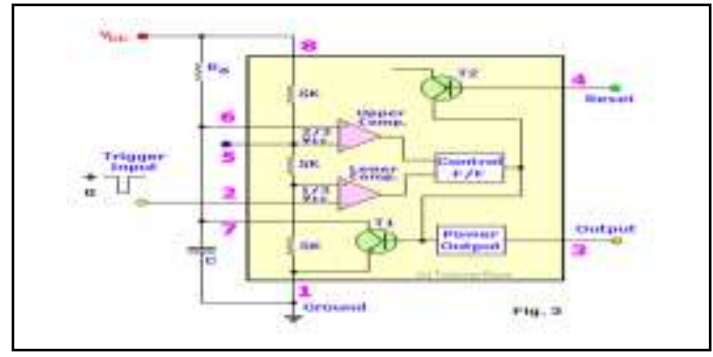

Fig.2.2: Internal view of a NE55 timer IC

\section{C) BISTABLE MULTIVIBRATOR}

In this proposed system 555 Timer IC work as a Bistable mode, both the states are stable. Means it remains in the same state (either HIGH or LOW) until an external trigger is applied; otherwise it stays in one of the two states (HIGH or LOW) indefinitely. The states are controlled by the Trigger PIN 2 and the RESET PIN 4. In bistable mode there is no RC network like the other two modes of 555, hence there are no equations and wave form. Bistable mode simply works on SR Flip-flop.

\section{CIRCUIT DIAGRAM}

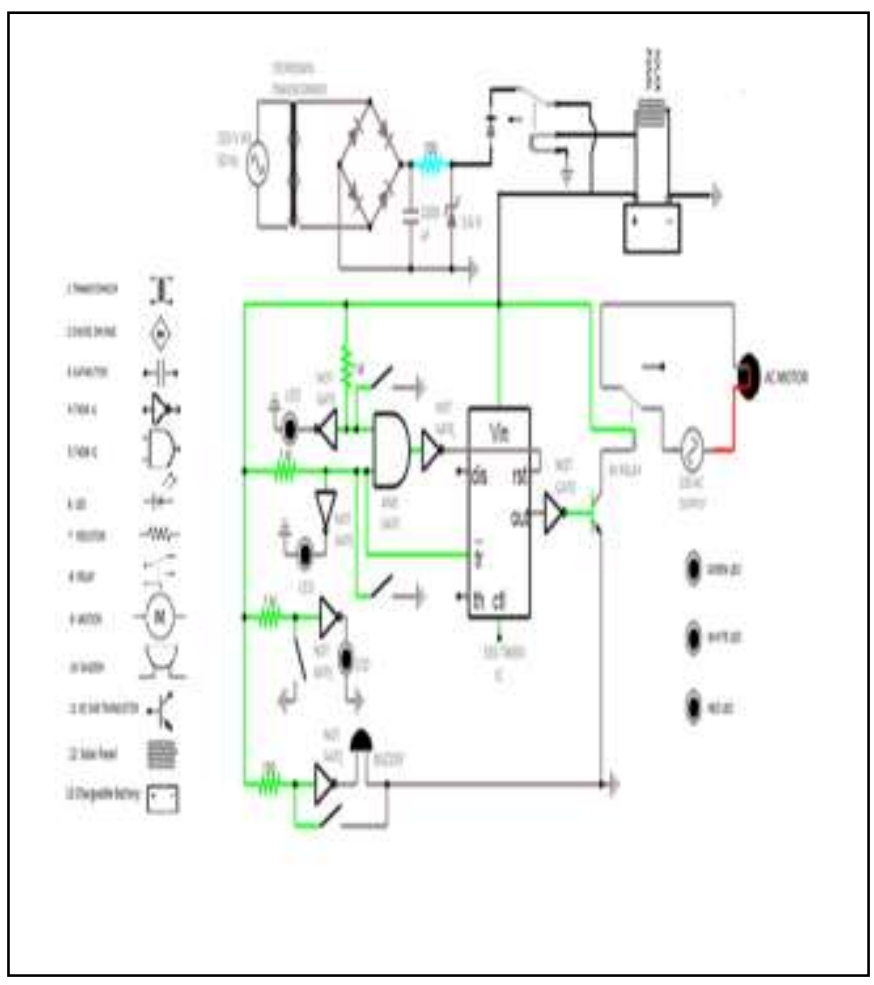

Fig.2.3: Shows circuit diagram of proposed logical automatic water control system

\section{LOGICAL TABLE}

\begin{tabular}{|c|c|c|c|c|c|c|c|c|c|c|}
\hline WDEA & INW & का & INWIT & 10 & WIT & SSS กMES & NOT & IfD & BWER & Qü \\
\hline IEVE! & SENW & Sork & Stoks & oumpit & outst & arps & oums & STATE & statk & gxt: \\
\hline 8 & A & 8 & C & & & & & & & \\
\hline OA & 1 & 1 & 1 & 1 & $\theta$ & $\theta$ & 1 & $\begin{array}{l}\text { LED6 } \\
\text { Off }\end{array}$ & Off & 65 \\
\hline 36 & 1 & 1 & 0 & 1 & 8 & $\$$ & 1 & $\begin{array}{l}\text { GEEH } \\
\text { (11) }\end{array}$ & OPF & 60 \\
\hline XS & 1 & 0 & 0 & 0 & 1 & 8 & 1 & $\begin{array}{l}\text { WallE } \\
\text { ing }\end{array}$ & ON & $\mathrm{CH}$ \\
\hline $5 \%$ & 0 & 0 & 0 & 0 & 1 & 1 & $\theta$ & $\begin{array}{l}\text { n:0 } \\
\text { IDD }\end{array}$ & ON & off \\
\hline & & & & & & & & & & \\
\hline
\end{tabular}

\section{CONCLUSION}

This system is very efficacious to overcome the water crisis in the world and it is very effective and sound then tradition method which includes mechanical floating probe methods. This system is all depend on digital signals and turn ON/OFF the pump according to the water levels. It shows excellent performance with its reliable digital technology and it is cheaper and durable. It should be implemented at every area whether; it came in rural or urban sector. Need of water is very cardinal to every living organism so, it's our duty to develop new ways to save it from wastage and preserve it for are next generations.

\section{ACKNOWLEDGMENT}

The support of Department of Electrical Engineering University of Engineering and Technology, Taxila is greatly acknowledged.

\section{REFERENCES}

[1] H.M.Chen; Z.Y.Chen; J.P.Su. "Design of a Sliding Mode Controller for a Water Tank Liquid Level Control System,”. $2^{\text {nd }}$ International conference 2007, Innovative Computing, Information and Control, (ICICIC) Kumamoto 2007, pp.335.

[2] A.Ning. and A.Yu "A water level controller for greenhouse sump tank,". second International conference, Mechanic Automation and control Engineering, (MACE) Hohhot, 2011.

[3] H.Chen and Z.Chen "Design of a composite of sliding mode controller applied to water level control for a water tank level system,". Control conference Kunming, 2008.

[4] E.J. Cho and F.V. Bright "Integrated chemical sensor array platform based on light emitting diode, xerogel-derived sensor elements, and high-speed pin printing," Analytica Chimica Acta, 2002, vol. 470, pp. 101-110.

[5] V. Bhambani and Y. Q. Chen "Experimental study of fractional order proportional integral (FOPI) controller for water level control,”. 47th conference on Decision and Control, Institute of Electrical and Electronics Engineering, (IEEE) Cancun 2008.

[6] L. Byrne, K.T. Lau, and D. Diamond "Monitoring of headspace total volatile basic nitrogen from selected fish species using reflectance spectroscopic measurements of pH sensitive filmsî, The Analyst," 2002, vol. 127, pp. 1338-1341

[7] A. Yazdizadeh, A. Mehrafrooz., K. D. Farahani and R. Barzamini. "Adaptive PID Controller design with application to non linear water level in NEKA power plant".4th International Symposium , 
Proc. of Sixth International Conference On Advances in Computing, Electronics and Electrical Technology - CEET 2016 Copyright (C) Institute of Research Engineers and Doctors. All rights reserved.

ISBN no. 978-1-63248-109-2 doi: 10.15224/ 978-1-63248-109-2-40

Communications, Control and Signal Processing, (ISCCSP) Limas sol. 2014,

[8] R. Sojoudizadeh, S. Aminifar, M. A. Daneshwar, G. Yosefi "Design of a new intelligent CMOS controller chip for control water level in tanks,". 2nd International conference, (volume: 5), Education Technology and Computer (ICETC) Shanghai 2010.

[9] M. Javanmard, K.A. Abbas and F. Arvin, "A Microcontroller-Based Monitoring System for Batch Tea Dryer," CCSE Journal of Agricultural Science, Vol. 1, No. 2, December 2009.

[10] A. A. M. Eltaieb and Z. J. Min "Automatic water level control system”. International Journal of Science and Research, (IJSR), 2014.
[11] I. C. MURMU and L. K. YADAV "LOW COST AUTOMATIC WATER LEVEL CONTROL FOR DOMESTIC APPLICATIONS," unpublished.

[12] S. M. S. Reza, W. Hasan and D. A. Hossain "Implementation of an Object Detector \& Wireless Signal Transmission System,". Proc. of The Fifth Intl. Conf. On Advances in Computing, Electronics and Electrical Technology - CEET 2016.

[13] http//www. wikipedia.com

About Author (s):

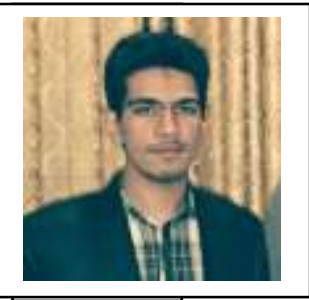

AUTHOR: HASSAN JAMAL

Doing BSc Electrical Engineering, from

University of Engineering and

Technology, Taxila.

Ph. no: $+92-3360471569$ 